\title{
Serological diagnostics of myocardium diseases based on multivariate analysis of cardiotrophic autoantibodies' profiles
}

\author{
Olga Moiseeva ${ }^{1}$, Lubov Mitrofanova ${ }^{1}$, Elena Karelkina ${ }^{1}$, Dmitry Zverev ${ }^{1}$, Dmitry Lebedev ${ }^{1}$, \\ Serge Skurydin ${ }^{2^{*}}$, Alexander Poletaev ${ }^{2,3}$ \\ ${ }^{1}$ V.A. Almazov's Federal Center for Heart, Blood and Endocrinology, St. Petersburg, Russia \\ ${ }^{2}$ Medical Research Center "Immunculus", Moscow, Russia; ${ }^{*}$ Corresponding Author: skurydinsv@immunculus.ru \\ ${ }^{3}$ P.K. Anokhin Research Institute of Normal Physiology, RAMS, Moscow, Russia
}

Received 2 November 2011; revised 16 December 2011; accepted 30 January 2012

\begin{abstract}
We analyzed profiles of IgG autoantibodies to 16 cardiac specific proteins and their main immunogenic region B-epitopes, in the groups of already verified cardiac pathology: acute and chronic lymphocytic myocarditis, ST elevation myocardial infarction, postinfarction remodeling of myocardium, dilated cardiomyopathy and in healthy controls along with patients, suffered from gastritis (to evaluate immune response against cross-reactive B-epitopes). AAB specific patterns allowed us to distinguish cases among themselves by means of multiparametrical canonical discriminant analysis in approximately $95 \%$ of cases. Positive predictive value in the group of MYO reached $95 \%$, in the STEMI- $89 \%$, in the PIR-99\%, in the DCM-99\%, in the group of gastritis-88\%. Principal component analysis of mentioned cardiac pathologies extended current clinical knowledge of their immunopathogenesis. Obtained data markedly proved a usability of serum AAB profiling for non invasive screening, differential diagnostics and working hypothesis composition.
\end{abstract}

Keywords: Autoantibody; Autoimmunity; B-Epitope; Autoantibody Profiling; Cardiology; Principal Component Analysis

\section{INTRODUCTION}

Alongside with direct damaging effect of infection or toxic agent, autoimmune pathology seems to be important in the pathogenesis of myocardium inflammatory diseases. However our ideas about autoimmune pathogenesis are based on indirect descriptive data only. Main stream in current clinical research is to estimate onedi- mensional laboratory marker or single clinical effect, especially by means of multicenter clinical analysis, which proves, for example, that the raised risk of dilated cardiomyopathy development is accompanied with elevation of autoantibody (AAB) against beta1-adrenoreceptor [1-3]. But there is always a problem: what is the causeeffect relationship between the disease and accompanying immunologic deviations, especially if to look at issue from position of immunophysiology and natural immunoregulation [4]

Primary conception about the destructive role of any autoimmune response was related to "horror autotoxicus" concept by Paul Ehrlich [5]. However, the initial idea has undergone an essential transformational challenge. The basis of modern conception of immunity and autoimmunity has been founded by Ilya Mechnikov, who argued the immune system not to be designed for much defense against microorganisms, but for dynamical maintenance of "harmonious state" in the conditions of constant pressure of Environment [6]. Development of Mechnikov's concept has led to understanding that one of basic function of immune system is rather Self-identifycation, Selfmaintenance, and Selfreparation throughout a life [7,8], without focusing on antiinfectious protection. Really normal microflora of mucous membranes is involved in human homeostasis and plays important role in many physiologic functions. For example, saprophytes in the gut take part in food digestion and utilization as well as in production of vitamins [9]. Thus, it is evident, that the immune system ignores normal microflora, and the primary function of immune system is not so much devoted to eliminate foreign genetic material [10] but to maintain of basic homeostasis of the body [11-14]. Thus autoimmunity can be surveyed, on the one hand, as the important instrument of cell death or harmful metabolic yields elimination from an organism, and on another hand - as the instrument of immunochemical regulation 
of homeostasis, alongside with neurologic and endocrinologic regulation [12,14-16].

All lymphocytes, matured in thymic cortex and medulla-have undergone positive and negative selection, and thus have become moderately autoreactive $[17,18]$, and autoreactive potential of the lasts is controlled by tolerogenic mechanisms of antibody idiotypic networks and Tregs [19-21]. Kovalyov was the first who described the concordance between the levels of serum $\mathrm{AAB}$ and the levels of binding autoantigens [22-24]. Accordingly to Kovalyov, the interconnected cellular and humoral immunity provides permanent balanced production of great amount of natural immunoglobulin-like molecules (i.e. AABs, BCRs and TCRs) in every health person for clearance purposes [11], supporting immunochemical homeostasis of the whole body. Proceeding from Kovalyov rule [24], AAB repertoire can serve as a mirror of individual enzyme and protein reactivity, imprinting organ- and tissue-specific disorders (feed-back principle). In case of a disease, primary pathological process in any organ may occur. It causes excessive cell death, activetion of necroptosis in spite of normal physiological apoptosis [25], and leads to excessive autoantigen presentation. Induction of destructive process in any organ or tissue causes excessive cell death and consequent activetion of B- and T-lymphocytes by apoptic debris and abundant exosomes [26], subclinical autoimmunization $[27,28]$ and secondary (compensatory) elevation of appropriate AABs $[11,29]$. Such secondary autoimmune responses are forwarded to clearance and reparation purposes in the affected organ, in opposite to primary or pathogenic autoimmune reactions based on genetic defects of immunoregulation, which cause multiple deviations [8]. In both cases (sanogenic as well as pathogenic), individual elevation of serum $\mathrm{AAB}$ level is predictive marker of organ specific cell death, autoimmunization, and beginning (or present now) pathologic process [30].

The aim of investigating AABs' profiles was to develop the specific combination of markers to predict the cardiac pathology and to esteem their contribution in the immunopathogenesis.

\section{MATERIALS AND METHODS}

\subsection{Patients}

17 patients with acute and chronic lymphocytic myocarditis (the group Myo) were examined. The diagnosis of myocarditis had been verified on the basis of Dallas Criteria and immunohistochemical analysis of an endomyocardial biopsy at patients with recently sustained heart failure and life threatening ventricular arrhythmia. Multiple biopsies (4 to 6) were taken from the right ventricle according to standardized techniques to confirm lymphocytic myocardial infiltration. The immunohistochemical analysis of biopsy specimens was made by monoclonal antibody staining against $\mathrm{CD} 3, \mathrm{CD} 4, \mathrm{CD} 8$, CD20, CD68 and HLA-DR (DAKO, Denmark). The second group with ST elevation myocardial infarction (STEMI) included 9 patients, who were inspected on 2 - 4 days of the disease. The average serum level of troponin I was elevated significantly $(32.3 \mathrm{ng} / \mathrm{ml})$ in the STEMI group. The third group included 8 patients with postinfarction remodeling of myocardium (PIR). The fourth group of dilated cardiomyopathy (DCM) included 11 patients.

When using coronarography, we had excluded all the cases with heart failure of an ischemic genesis and myocarditis (according to endomyocardial biopsy) from this group. The additional clinical aspect of patients with a cardiovascular pathology is presented in Table 1. The

Table 1. Clinical profile of groups with a cardiovascular pathology. Abbreviations: FC — functional class, LAD — left atrial diameter, LVEDD - left ventricular end diastolic diameter, LVESD—left ventricular end systolic diameter, IVSd — LV interventricular septal wall thickness in diastole, PWd - LV posterior wall thickness in diastole, EF—ejection fraction by Simpson's rule.

\begin{tabular}{|c|c|c|c|c|}
\hline & $\begin{array}{c}\text { Myocarditis M } \pm \text { SD } \\
\mathrm{n}=17\end{array}$ & $\begin{array}{l}\text { STEMI M } \pm \text { SD } \\
n=9\end{array}$ & $\begin{array}{c}\mathrm{PIR} M \pm \mathrm{SD} \\
\mathrm{n}=8\end{array}$ & $\begin{array}{c}\mathrm{DCM} \mathrm{M} \pm \mathrm{SD} \\
\mathrm{n}=11\end{array}$ \\
\hline Age, years & $37.8 \pm 14.1$ & $62.7 \pm 9.4$ & $49.9 \pm 6.8$ & $41.5 \pm 15.3$ \\
\hline Gender (m:f) & $11: 6$ & $6: 3$ & 8:0 & $6: 5$ \\
\hline Body mass index, $\mathrm{kg} / \mathrm{m}^{2}$ & $26.5 \pm 3.3$ & $28.7 \pm 5.7$ & $29.4 \pm 4.8$ & $28.6 \pm 6.9$ \\
\hline $\begin{array}{l}\text { CHF FC-NYHA } \\
\text { STEMI group FC-Killip }\end{array}$ & $2.2 \pm 1.2$ & $1.0 \pm 0.5$ & $2.8 \pm 0.6$ & $2.5 \pm 0.7$ \\
\hline \multicolumn{5}{|c|}{ Ultrasound of the heart and vessels } \\
\hline $\mathrm{LAD}, \mathrm{mm}$ & $42.3 \pm 6.5$ & $42.0 \pm 6.5$ & $44.3 \pm 5.4$ & $46.8 \pm 4.1$ \\
\hline LVEDD, mm & $57.8 \pm 7.5$ & $50.2 \pm 7.1$ & $67.4 \pm 4.9$ & $66.6 \pm 7.0$ \\
\hline LVESD, mm & $43.9 \pm 11.2$ & $37.7 \pm 9.3$ & $56.7 \pm 6.6$ & $57.7 \pm 8.3$ \\
\hline IVSd, mm & $10.3 \pm 1.4$ & $11.5 \pm 2.7$ & $10.1 \pm 3.4$ & $10.2 \pm 1.7$ \\
\hline PWd, mm & $9.7 \pm 1.8$ & $11.2 \pm 1.0$ & $9.7 \pm 0.6$ & $9.5 \pm 1.5$ \\
\hline $\mathrm{EF}, \%$ & $43.8 \pm 17.8$ & $45.7 \pm 14.8$ & $27.1 \pm 7.6$ & $28.7 \pm 6.6$ \\
\hline
\end{tabular}


first control group (control group I, Health) contained 18 practically healthy volunteers $(\mathrm{m}=8, \mathrm{f}=10$; age 24 - 55 years; average age 39 years). The second control group (control group II, Gastritis) contained 8 patients without the signs of a cardiac pathology, but with chronic gastritis, endoscopy confirmed $(\mathrm{m}=3, \mathrm{f}=5$; age $38-67$ years; average age 43 years).

\subsection{ELISA Methods}

Using standartized ELISA test systems for semi-quantitave serum AAB evaluation (ELI-TEST group by Medical Research Center "Immunculus", Moscow, Russia), we defined individual normalized levels of organ marker carditropic AABs against: cardiomyocyte cytoskeleton antigen CoM-02, cytoplasmic antigen of cardiomyocytes CoS-05-40, platelet antigen TrM-0.3, ANCA antigen, NO-synthetase (NOS), angiostatin, cardiomyosin L, collagen II and $\beta 2$-glycoprotein I. All antigens were purified in the MRC "Immunculus", as described [31]. Besides natural antigens synthetic 20-25-mer peptide fragments (epitopes) of adenine nucleotide translocator-1 and -2 (ANT-1 and ANT-2), PAPP-A, p53, cardiac-type myosinbinding protein $\mathrm{C}$ (MyBPC3), and an extracellular loop of $\beta 1$-adrenoreceptor, had been used (all produced by "Peptide 2.0 Inc." (Chantilly, USA)).

Mean individual immunoreactivity and normalized serum AAB level to each natural antigen or synthetic fragment was estimated as described [32]. Besides, we analyzed specific multivariate features of AABs' profiles (integral autoreactivity pattern), i.e. spikes of normalized AAB level, starting from mean individual immunoreactivity level that was performed for every antigen to produce the profile $[4,33,34]$.

\subsection{Statistics}

The statistical analysis of the received data was made with nonparametric statistical methods (Mann-Whitney test, Chi-square test, Kruskal-Wallis test) and methods of multivariate analysis (principal component analysis PCA, canonical analysis CA, discriminant analysis DA) with the usage of software package Statistica 8.0. Exploratory application of PCA made it possible to transform significant correlations of numerous $\mathrm{AAB}$ content to induced variable format (principal components), that had facilitated a visual estimation of these AAB deviations and had allowed to discover linearly invisible factors, that did not exist before $[33,35,36]$. Discrimination rules had been produced to analyze specific features of AABs' profile of each patient. Canonical functions along with PCA had been used to estimate visually peculiarities of each patient distribution in the uniform coordinate frame in which different nosology forms revealed their similarities and differences.

\subsection{Ethics}

The study was approved by the Local Ethic Committee of V.A. Almazov's Federal Center for Heart, Blood and Endocrinology.

\section{RESULTS}

\subsection{Serum Levels of Troponin I and IgG Autoantibodies to p53, to ANT-1, to MyBPC, to Cardiomyosin $L$ and to CoS-05-40 at Patients within MYO, STEMI, PIR and DCM Groups Significantly Differ}

Comparative clinico-immunological analysis of patients with myocarditis showed the raised troponin I serum level (the marker of myocardial leison) to be associated with elevation of $\mathrm{AAB}$ to protein $\mathrm{p} 53$ ( $\mathrm{rs}=0.651$; $\mathrm{p}<$ 0.01 ). Along with it, higher troponin I level, $12.3 \pm 3.9$ $\mathrm{ng} / \mathrm{ml}$ against $2.0 \pm 3.5 \mathrm{ng} / \mathrm{ml}(\mathrm{p}<0.05)$ in other cases, was determined at patients with raised $\mathrm{AAB}$ to protein MyBPC3. Elevated histological ratio of cardiomyocyte necrosis in myocardium specimens had been closely related to elevated AAB to $\mathrm{CoS}-05-40\left(\chi^{2}=6.52 ; \mathrm{p}<0.05\right)$ and to cardiomyosin $\mathrm{L}\left(\chi^{2}=6.52 ; \mathrm{p}<0.05\right)$.

AAB profiling of patients within MYO, STEMI, PIR and DCM groups had shown significant intergroup differences of AAB distribution for cardiomyocyte cytoskeleton CoM-02 antigen $\left(\chi^{2}=21.7 ; \mathrm{p}<0.01\right)$ and cardiomyosin $\mathrm{L}\left(\chi^{2}=21.3 ; \mathrm{p}<0.01\right)$. In details, for the cases in STEMI and MYO groups the raised profile was significantly higher, than in the control groups, whereas for patients with PIR and DCM it essentially did not differ from normal controls. Direct correlation dependence between the level of AAB towards main immunogenic region of ANT-1 and ejection fraction ( $\mathrm{rs}=0.362 ; \mathrm{p}<$ 0.05) was established. The similar was also found between the level of AAB to a fragment of an extracellular loop of $\beta 1$-adrenoreceptor and the left ventricle dimensions: $\operatorname{LV} \operatorname{EDV}(\mathrm{rs}=0.404 ; \mathrm{p}=0.02)$ and $\operatorname{LV} \operatorname{ESV}(\mathrm{rs}=$ $0.436 ; \mathrm{p}=0.013)$.

\subsection{Linear Differences of AABs Are Not Specific for Each of Described Cardiac Pathology, while AAB Profiling Reveals Intergroup Differences}

Despite intergroup linear differences (Kruskal-Wallis test, $\mathrm{p}<0.05$; Median test, $\mathrm{p}<0.05$ ) (Figure 1), our attempts to discriminate blindly the inspected patients to one of the 5 clinical groups (myocarditis, acute myocardial infarction, postinfarction remodeling, chronic gastritis and practically healthy cases), only on the basis of absolute values of a single serum antibody, had appeared 
ineffective. During the same time, analysis of the individual profiles, previously described in $[4,12]$, having reflected relative interconnections in a content of numerous AABs (the pattern of integral autoreactivity of a patient), had allowed us to discover significant inter- group differences for several antigens. The cases of each group possessed their representative AABs' profiles, which had made it possible to significantly distinguish patients among themselves by means of canonical discriminant analysis (Figure 2).

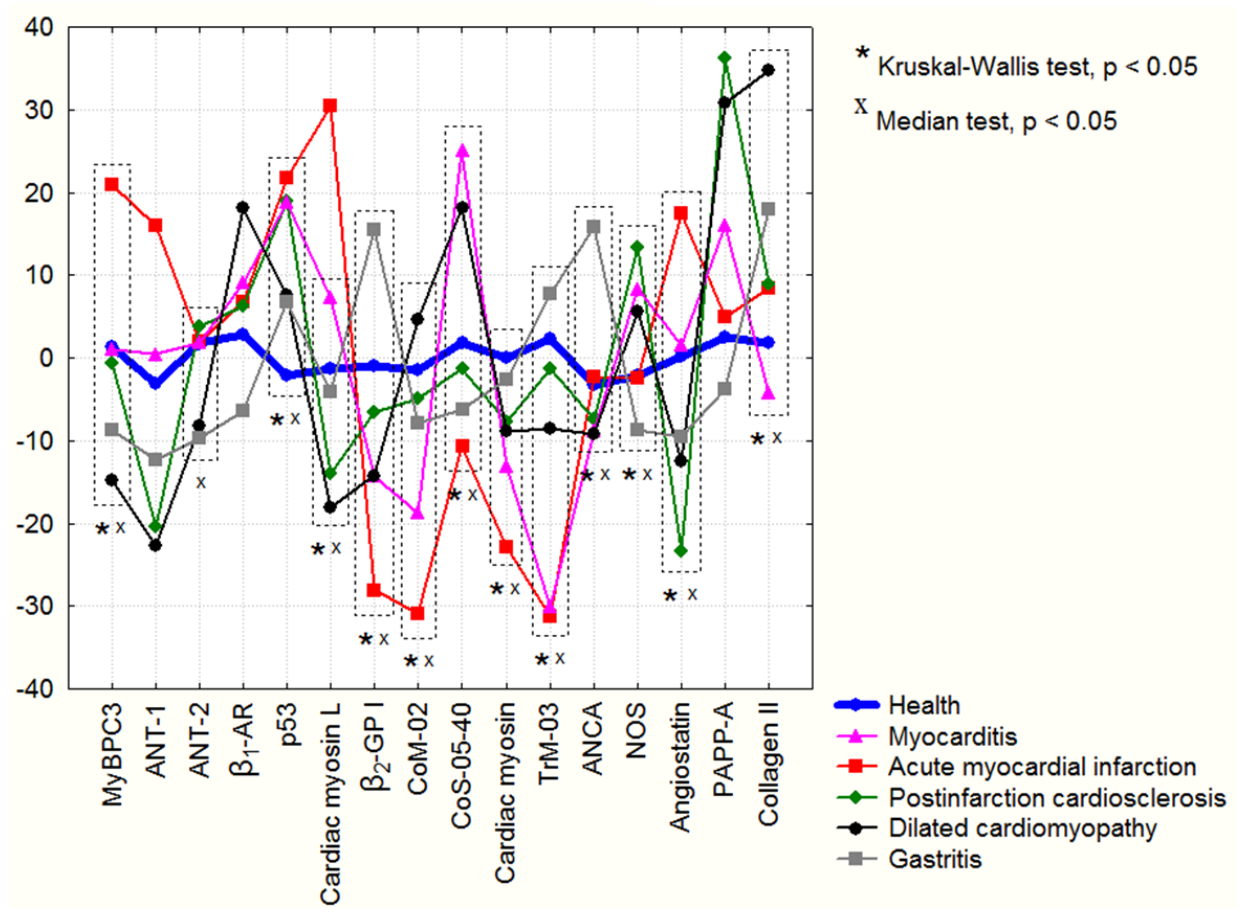

Figure 1. AABs' profiles, appropriate of different clinical groups (based on average values).

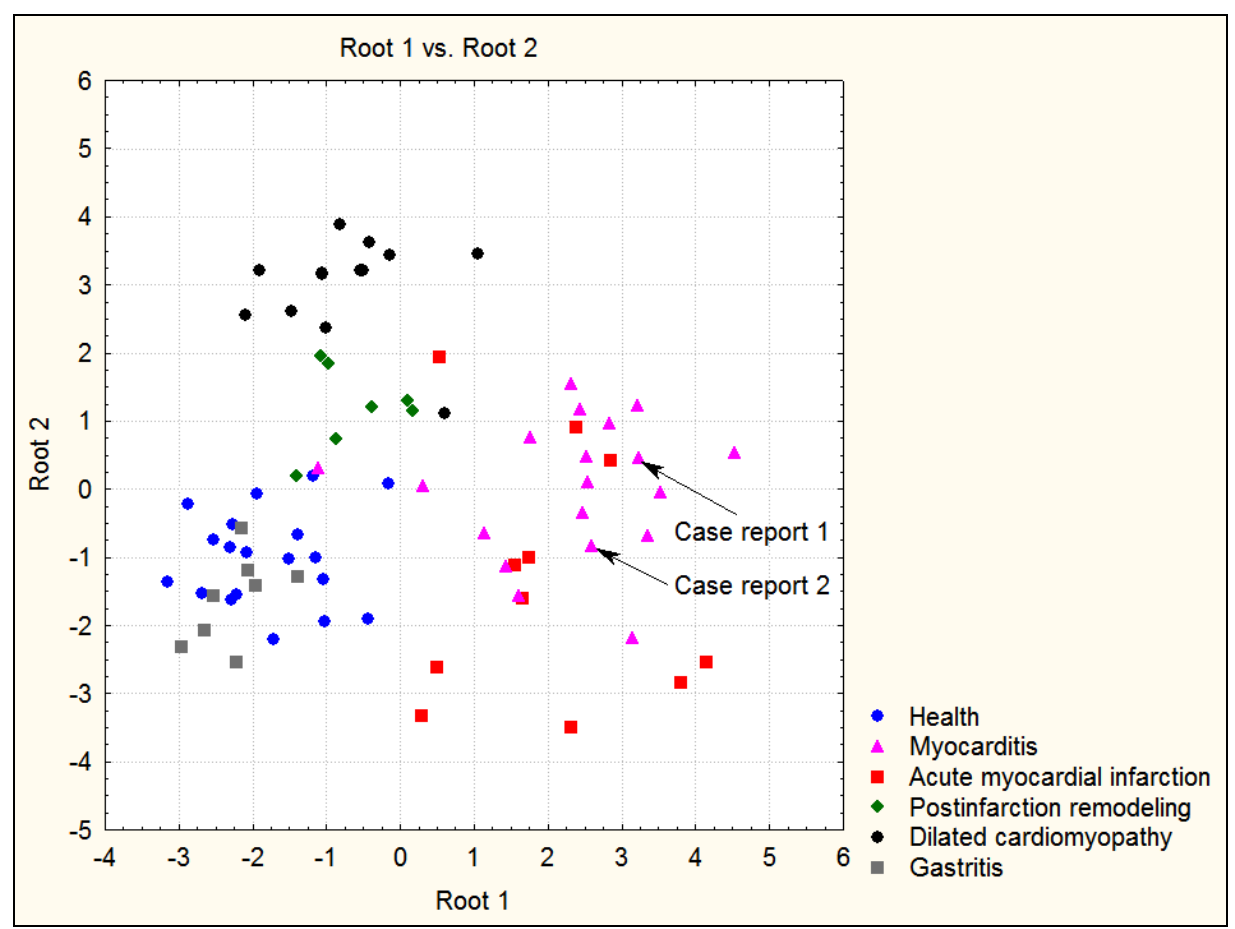

Figure 2. Map of projections of canonical factor loads of cardiac patients on the axes of canonical roots (based on AABs' profiles and their correlations). 


\subsection{Multivariate Analysis of AABs' Distribution (PCA, CA, DA) at Cardiac Pathology Provides Additional Information about Its Immunopathogenesis}

Using a multiparametrical factor analysis for study of AABs' profiles of patients in the STEMI group, some regularity in profile distribution had been noted (Tables 2 and 3). In the structure of the first principal component at patients with acute myocardial infarction the basic contribution was made by variance in content of $\mathrm{AAB}$ to ANT, MyBPC3, cardiomyosin. The factor loadings by marker AABs to ANCA, $\beta 2$-GP I and TrM- 0.3 had appeared to become essential less (being loaded of the 2nd and 3rd factors). Marker AAB to $\beta 1$-AR loaded the structure of the 5th principal component.

Marker AABs' profile, specific for MYO, looked a little

Table 2. The contribution of some AABs in the structure of principal components of cardiac clinical groups. Digits designate sequence numbers of corresponding principal components. For simplification of interpreting only the first 7 principal components from each group are chosen. The criterion of variable inclusion (i.e. marker AAB) in a certain principal component is considered, if factor weight of a variable $\mathrm{AAB}$ for this component exceeded more than 0.7 . Empty cells mean the presence of minor residual correlation or insignificant factor weight of $\mathrm{AAB}$ outside of 7 principal components. For simplification of interpreting, each cell is coloured in a spectrum range: from red (the less significant 7 th component) to violet (the most significant 1 st component).

\begin{tabular}{|c|c|c|c|c|c|c|}
\hline $\mathrm{AAB}$ to $\mathrm{AG}$ & Health & Myocarditis & $\begin{array}{l}\text { Acute myocardial } \\
\text { infarction }\end{array}$ & $\begin{array}{l}\text { Postinfarction } \\
\text { remodeling }\end{array}$ & $\begin{array}{c}\text { Dilated } \\
\text { cardiomyopathy }\end{array}$ & Gastritis \\
\hline МyBPC3 & 2 & & 1 & 3 & 6 & 3 \\
\hline ANT-1 (epitope VDP) & 4 & & 1 & 5 & 5 & 3 \\
\hline ANT-2 (epitope EGS) & 7 & & 1 & 3 & & 3 \\
\hline$\beta_{1}$-AR & 1 & 3 & 5 & & 4 & 5 \\
\hline p53 & 5 & 7 & & & 2 & 1 \\
\hline Cardiac myosin L & & & & 2 & 1 & 1 \\
\hline$\beta_{2}$-GP & 3 & 2 & 3 & & 3 & \\
\hline CoM- 02 & & 1 & 1 & & 2 & 1 \\
\hline CoS-05-40 & 3 & 2 & 4 & 1 & & 4 \\
\hline Cardiac myosin & 1 & 1 & 1 & 3 & & \\
\hline TrM-0.3 & 5 & 5 & 3 & 3 & 2 & 4 \\
\hline ANCA & 2 & 4 & 2 & 4 & 5 & 5 \\
\hline NOS & 6 & 6 & 5 & 2 & & \\
\hline Angiostatin & & & 7 & 1 & & 2 \\
\hline PPAP-A & 3 & & 4 & 2 & 7 & 1 \\
\hline Collagen II & 1 & 2 & 6 & 2 & 2 & 2 \\
\hline
\end{tabular}

Table 3. Cumulative eigenvalues for denoted principal components.

\begin{tabular}{|c|c|c|c|c|c|c|}
\hline $\begin{array}{c}\text { Principal } \\
\text { components }\end{array}$ & Health & Myocarditis & $\begin{array}{c}\text { Acute } \\
\text { myocardial } \\
\text { infarction }\end{array}$ & $\begin{array}{l}\text { Postinfarction } \\
\text { remodeling }\end{array}$ & $\begin{array}{c}\text { Dilated } \\
\text { cardiomyopathy }\end{array}$ & Gastritis \\
\hline 1 & $22.91 \%$ & $37.21 \%$ & $39.24 \%$ & $40.48 \%$ & $46.16 \%$ & $49.01 \%$ \\
\hline 2 & $39.80 \%$ & $58.62 \%$ & $59.84 \%$ & $65.42 \%$ & $63.31 \%$ & $65.64 \%$ \\
\hline 3 & $54.62 \%$ & $69.29 \%$ & $73.47 \%$ & $85.52 \%$ & $74.37 \%$ & $77.96 \%$ \\
\hline 4 & $64.42 \%$ & $76.34 \%$ & $81.30 \%$ & $95.05 \%$ & $82.26 \%$ & $86.58 \%$ \\
\hline 5 & $73.45 \%$ & $82.32 \%$ & $87.82 \%$ & $98.18 \%$ & $89.20 \%$ & $93.22 \%$ \\
\hline 6 & $81.48 \%$ & $87.54 \%$ & $93.45 \%$ & $100.00 \%$ & $94.18 \%$ & $96.95 \%$ \\
\hline
\end{tabular}


differently. The structure of the first principal component was loaded by AAB to cardiomyosin and to cardiomyocyte cytoskeleton CoM-02 antigen. Marker AAB to $\beta 2$ GP I took a place in the second principal component, as well as AAB to collagen and to CoS-05-40 antigen. Marker $\mathrm{AAB}$ to $\beta 1$-adrenoreceptor also enlarged their weight, being risen from the 5 th component in the STEMI group to the 3rd component in MYO. At the same time AAB to ANCA, whose modifications were evidently expressed in STEMI, had achieved the low factor importance at the myocarditis group, being taken a place of the 4th principal component.

In the PIR group the first principal component was presented by AAB to angiostatin and to CoS-05-40 antigen. The structure of the second principal component was loaded by AAB to collagen, PAPP-A, NOS and myosin light chain. The structure of the third principal component of PIR was loaded by AAB to ANT, MyBPC3, cardiomyosin and to platelet TrM-03 antigen.

In the DCM group the first principal component was presented by AAB to a myosin light chain. The structure of the second principal component was filled with AAB to apoptosis regulator p53 and platelet TrM-0.3 antigen. Factor weight of AAB to ANT, MyBPC3 and PAPP-A had appeared to be the least in the DCM group.

At visual analysis of AABs' profiles of various forms of a cardiac pathology, some general lines in allocation of AAB peaks had been noted. It is worth saying, that factor similarity of group pairs: MYO and STEMI, PIR and DCM, was discovered. Analysis of principal component allocation had allowed us to differentiate the specified clinical groups by means of several marker AABs (Tables 2 and 3). In other words, if not mentioning mutual immunopathogenic load of AABs, the basic discriminants in the groups of MYO and STEMI had appeared to be AABs towards MyBPC3, ANT, ANCA, CoS-05-40 and to collagen II. The groups of PIR and $\mathrm{DCM}$ were differentiated by $\mathrm{AAB}$ to plasminogen, NOS, CoM-02, MyBPC3, ANT-2, $\beta 2-$ GP. The gastritis group differed from the control group of healthy donors by AAB to cardiomyosin L, cardiomyosin, plasminogen, $\beta 1$-AR, p53, CoM-02, ANT-2, ANCA.

At discriminant analysis of all groups simultaneously among themselves there were discovered significant deviations in content of several AABs, whose had been arranged in order of decreasing their significance level $\mathrm{p}(\mathrm{DA}, \mathrm{F}=5.79, \mathrm{p}<0.006)$ : TrM-0.3, collagen, PAPP-A, p53, angiostatin, $\beta 1-\mathrm{AR}, \mathrm{CoS}-05-40, \beta 2-\mathrm{GP}$, CoM-02, NOS, ANCA, cardiomyosin L.

\subsection{AAB Profiling Provides Extra Help for Making Diagnosis of Cardiac Pathology}

By means of AABs' profile usage it had become possible to confirm the diagnosis or to assign a patient to a control health group in almost all of the cases. Usage of discriminant analysis made it possible to diagnose correctly the nosology in $95 \%$ of cases, varying among the groups from $88 \%$ (gastritis) to $100 \%$ (myocarditis) (Figures 2 and Table 4).

For application and choice of maximum value of each of 6 discriminant functions (diagnosis establishment), we had been discovered the conforming quotients and constants. However for an approximate assessment of a state of the patient (Figure 2) and making the provisional diagnosis, it was possible to take advantage of graphic construction with the usage of canonical functions.

Let's examine two specific cases.

Case Report 1. The patient M. of 32 years (f), was hospitalised with complaints of sharp weakness and tachycardia at the minimum physical effort and at rest. Two months ago she had overcome a viral infection. At a transthoracic echocardiography the dilatation of left chambers of the heart with depression of global contractility and rising of pulmonary pressure was revealed. In

Table 4. Matrix of discriminant classifications for 6 clinical groups. In the first two columns there are primary clinical classifications, in remaining columns - the predicted classifications via $\mathrm{AAB}$ profiles.

\begin{tabular}{|c|c|c|c|c|c|c|c|}
\hline & $\begin{array}{l}\text { Percent } \\
\text { Correct }\end{array}$ & $\begin{array}{l}\text { Health } \\
(\mathrm{n}=20)\end{array}$ & $\begin{array}{l}\text { Myocarditis } \\
\quad(\mathrm{n}=18)\end{array}$ & $\begin{array}{l}\text { Acute myocardial } \\
\text { infarction }(\mathrm{n}=8)\end{array}$ & $\begin{array}{l}\text { Postinfarction } \\
\text { remodeling } \\
(\mathrm{n}=5)\end{array}$ & $\begin{array}{l}\text { Dilated cardiomyopathy } \\
\qquad(\mathrm{n}=14)\end{array}$ & $\begin{array}{c}\text { Gastritis } \\
(\mathrm{n}=8)\end{array}$ \\
\hline Health & 95 & 18 & & & & & 1 \\
\hline Myocarditis & 95 & 1 & 18 & & & & \\
\hline $\begin{array}{l}\text { Acute myocardial } \\
\text { infarction }\end{array}$ & 89 & 0 & & 8 & & 1 & \\
\hline $\begin{array}{l}\text { Postinfarction } \\
\text { remodeling }\end{array}$ & 100 & 0 & & & 5 & & \\
\hline Dilated cardiomyopathy & 100 & 0 & & & & 13 & \\
\hline Gastritis & 88 & 1 & & & & & 7 \\
\hline Total & 95 & 20 & 18 & 8 & 5 & 14 & 8 \\
\hline
\end{tabular}


addition, arisen blood levels of troponin I $(15.2 \mathrm{ng} / \mathrm{ml})$, C-reactive protein $(6.13 \mathrm{mg} / \mathrm{l})$ and NT-proBNP (1996 $\mathrm{pg} / \mathrm{ml}$ ) was found. Coronarography showed coronary arteries to be without indications of any atherosclerotic lesion, blood supply was not disturbed. Pressure in the right ventricle was of 53/12 $\mathrm{mm} \mathrm{Hg}$. Necrosis of cardiomyocytes with lymphocytic and macrophage infiltration was determined, along with perimuscular fibrosis, HLA-DR-antigen expression on endothelium and on infiltrating cells at endomyocardial biopsy. Magnetic resonance tomography had confirmed diffuse myocardial changes of an inflammatory character. There were no PCR signs of gene elements of adenovirus, enterovirus, HHV6, Parvovirus B19, CMV, EBV in situ in any biopsy samples of the myocardium. During examination of AABs' profiles, some AAB rising towards peptide fragments of Adenine nucleotide translocator 1 and 2, p53, cytoplasmic antigen of cardiomyocytes CoS-05-40, cardiomyosin $\mathrm{L}$ and platelet antigen TrM-0.3 was observed.

Case Report 2. Patient T., 27 years old (m), was hospitalised for percutaneous CARTO-guided catheter radiofrequency ablation of ventricular arrhythmia. Ventricular disturbances came to be evident within last 2 years. Medicamental antiarrhytmic therapy was without any essential effect. The patient noted transient loss of consciousness. At Holter monitoring there were Registered right ventricular extrasystoles up to 16708 times per day. The dimensions and contractility of the heart were without essential deviations from norm at a transthoracic echocardiography. Necrosis of cardiomyocytes, perivascular fibrosis, edema of myocardial stroma, lymphocytic infiltration and expression of HLA-DR on cells of an inflammatory infiltrate and an endothelium were observed at an endomyocardial biopsy. There were no any morphological signs of arrhythmogenic cardiomyopathy and amyloidosis. It was found, that enterovirus capsid protein VP1 had been expressed in myocardium via immunohistochemistry. There were found arisen $\mathrm{AAB}$ levels towards peptide fragments of Adenine nucleotide translocator 1 and 2, p53, myosin binding protein MyBPC3, cardiomyocyte cytoskeleton antigen CoM-02, platelet antigen TrM-0.3, ANCA antigen, cardiomyosin L and $\beta 2-$ glycoprotein I.

\section{DISCUSSION}

Nowadays diagnostics of inflammatory diseases of a myocardium represents essential difficulties. In view of lack of pathognomonic symptoms, and also low sensitivity and specificity of the majority of laboratory tests [37, 38] often there is a necessity of morphological refinement of the disease diagnosis. At the same time, for myocarditis intravital diagnostics it is used from 4 to 6 bioptate specimens, and the standard pathoanatomical research to make a diagnosis of myocarditis, assumed tak- ing not less than 17 samples (which were histology- cally proven in $80 \%$ of cases maximum) $[39,40]$. As a result, the sensitivity of endomyocardial biopsy at use of one biopsy specimen achieves $25 \%$, and it is not elevated above $50 \%$ at use of $4-5$ biopsy specimens. The raised level of troponin I as a marker of myocardial damage, is determined at $35 \%$ of patients with myocarditis and is characterised by high specificity (at about $89 \%$ ), but low sensitivity (about 34\%) [41]. Therefore, normal level of troponin or creatine kinase MB-fraction does not permit to exclude the diagnosis of myocarditis [41]. Low specificity and rather high sensitivity characterise scintigraphy of a myocardium by gallium- 67 and by antimyosin $A B$, labeled with indium-111 [42]. Last years the tomography is suited for non-invasive diagnostics of inflammatory diseases of a myocardium with gadolinium contrasting amplification, which allows at usage, at least, of 2 to 3 criteria (LGE, EGE, T2-WI) to diagnose myocarditis with sensitivity of $67 \%$ and specificity of $91 \%$ [43].

The present results show an effectiveness of immunochemical methods of diagnostics in cardiology. Without any detailed explanation of predicted role of AABs in immunopathogenesis of one or another cardiac nosology, whose load can be neutral, pathogenic or sanogenic, the variation of serum content of principal AABs is often the earliest and specific marker of any chronic pathologic process [30].

Recently undertaken attempts to use the titers of one or another "carditropic" AAB for diagnostics of myocardities have appeared not quite successful. For instance, it was shown, that raised AAB titers to sarcolemmal and myofibrillar proteins of cardiomyocytes were found not only in $12 \%-75 \%$ of patients with myocarditis and dilated cardiomyopathy, but also in $4 \%-34 \%$ of healthy persons [44-46]. Moreover, inflammatory diseases of a myocardium can reveal at normal level of some "carditropic" AABs [47-50]. Therefore interpretation and usage of AAB titers would become speculative and non evident until it is based only on laboratory referential "averaged norms". The data sets with similar medians but with different dispersions impose greatly on AABs' profile formation, without any appeal to mean laboratory norms. In this context we would like to cite Meroni (2007): “...The initial paradigm 'one autoantibody for one disease' does not appear to be useful any longer. An autoantibody profile does seem to offer more diagnostic and prognostic power than the determination of single autoantibody specificity. The consequence is the use of new assays to detect different autoantibodies" [34]. Backes C. and other write: "Instead of allocating single antigens to a specific group of diseases and even to a specific disease, it appears more appropriate to allocate seroreactivity patterns" [29]. This idea of autoantibody profiling is shown by us and others [29,34]. 
As the data in our work conveys, only such multi-dimensional approach provides high specific and sensitive discrimination of serums not only of cardiologic patients from serums of healthy persons, but also to differentiate various forms of a cardiac pathology and reveal molecular peculiarities of their immunopathogenesis.

It is worth saying, that the first and the second princepal component of each nosology suit common knowledge about its immunopathogenesis (Table 2). For example, it is well known about the principal role of myosin lesion in MYO, ATP deficiency in STEMI, collagen deposition in PIR, genetic defects of myosin in DCM. Moreover, analysis of further components gives valuable information about hidden processes of immunochemical metabolism (even in norm), which needs further investigation.

We suppose, that increasing the number of observations in a combination of usage of new perspective antigens will allow us to improve diagnostic value of discussed approach and to transform it from being a conforming method to become a highly informative and quite trivial differential-diagnostic laboratory procedure, along with assistance for working hypothesis composition.

Our findings demonstrate that circulating $\mathrm{AABs}$ and their profiles accompanying to several forms of cardiac pathology can be considered as a marker of developing disease, even not autoimmune by its origin, but with its own component weight of autoimmunity.

\section{ACKNOWLEDGEMENTS}

Authors thank Kilikovsky V.V. (RSMU, Moscow) for fruitful comments on usage of statistical methods and reviewing of manuscript.

\section{REFERENCES}

[1] Yoshikawa, T., Baba, A., and Nagatomo, Y. (2009) Autoimmune mechanisms underlying dilated cardiomyopathy. Circulation Journal, 73, 602-607. doi:10.1253/circj.CJ-08-1151

[2] Leiros, C.P., Sterin-Borda, L., and Borda, E. (1989) Betaadrenergic cardiac antibody in autoimmune myocarditis. Autoimmunity, 2, 223-234. doi:10.3109/08916938909014686

[3] Weller, A.H., Simpson, K., Herzum, M., Van Houten, N., and Huber, S.A. (1989) Coxsackievirus-B3-induced myocarditis: Virus receptor antibodies modulate myocarditis. Journal of Immunology, 143, 1843-1850.

[4] Poletaev, AB. (2010) Physiologic immunology (natural autoantibodies and problems of nanomedicine). MICLOSH, Moscow.

[5] Ehrlich, P. and Morgenroth, J. (1901) Zytotoxine als Antikorper. Wiener Klinische Wochenschrift, 38, 251-260.

[6] Metchnokoff, E. (1968) Immunity in infective diseases (Original published 1901). Johnson Reprint, New York.
[7] Cohen, I.R. (1993) The meaning of the immunological homunculus. Israel Journal of Medical Sciences, 29, 173174.

[8] Kosyakov, P.N. (1974) Isoantigens and isoantibodies of man in the norm and pathology. Meditsina, Moscow.

[9] Grubb, R., Midtvedt, T. and Norin, E. (1989) The regulatory and protective role of the normal microflora. Proceedings of the Fifth Bengt E. Gustafsson Symposium, Stockholm, 1-4 June 1988, Macmillan and Stockton Press, London and New York.

[10] Pradeu, T. and Carosella, E.D. (2006) On the definition of a criterion of immunogenicity. Proceedings of the $\mathrm{Na}$ tional Academy of Sciences of the USA, 103, 1785817861. doi:10.1073/pnas.0608683103

[11] Plotz, P.H. (2003) The autoantibody repertoire: Searching for order. Nature Reviews Immunology, 3, 73-78. doi:10.1038/nri976

[12] Poletaev, A.B., Stepanyuk, V.L. and Gershwin, M.E. (2008) Integrating immunity: The immunculus and self-reactivity. Journal of Autoimmunity, 30, 68-73. doi:10.1016/j.jaut.2007.11.012

[13] Voisin, G.A. (1998) Immunology understood through pregnancy. American Journal of Reproductive Immunology, 40, 124-129. doi:10.1111/j.1600-0897.1998.tb00403.x

[14] Tomer, Y. and Shoenfeld, Y. (1988) The significance of natural autoantibodies. Immunological Investigations, 17, 389-424. doi:10.3109/08820138809049846

[15] Elkon, K. and Casali, P. (2008) Nature and functions of autoantibodies. Nature Clinical Practice Rheumatology, 4, 491-498. doi:10.1038/ncprheum0895

[16] Grabar, P. (1968) About autoantibodies. In: Ado, A.D., Ed., Problems of reactivity in pathology, Meditsina, Moscow. 35-52.

[17] Ryan, K.R., Patel, S.D., Stephens, L.A. and Anderton, S.M. (2007) Death, adaptation and regulation: The three pillars of immune tolerance restrict the risk of autoimmune disease caused by molecular mimicry. Journal of Autoimmunity, 29, 262-271. doi:10.1016/j.jaut.2007.07.014

[18] Murphy, K. (2007) Janeway's immunobiology. Garland Science, New York.

[19] Youinou, P. (2007) B cell conducts the lymphocyte orchestra. Journal of Autoimmunity, 28, 143-151. doi:10.1016/j.jaut.2007.02.011

[20] McAleer, J., Weber, P., Sun, J. and Butler, J.E. (2005) Antibody repertoire development in fetal and neonatal piglets. XI. The thymic B-cell repertoire develops independently from that in blood and mesenteric lymph nodes. Immunology, 114, 171-183. doi:10.1111/j.1365-2567.2004.02101.x

[21] Hsieh, C.S., Zheng, Y., Liang, Y., Fontenot, J.D. and Rudensky, A.Y. (2006) An intersection between the self-reactive regulatory and nonregulatory $\mathrm{T}$ cell receptor repertoires. Nature Immunology, 7, 401-410. doi:10.1038/ni1318

[22] Kovalyov, L.I., Naumov, V.G., Pulyayeva, H.V., Samko, A.M., Tsvetkova, M.N., Shishkin, S.S. and Mukharlyamov, N.M. (1990) Two-dimensional electrophoresis of 
heart muscle proteins in human cardiomyopathies. Electrophoresis, 11, 333-336. doi:10.1002/elps.1150110412

[23] Kovalyova, M.A., Kovalyov, L.I., Toropygin, I.Y., Shigeev, S.V., Ivanov, A.V. and Shishkin, S.S. (2009) Proteomic analysis of human skeletal muscle ( $m$. vastus lateralis) proteins: Identification of 89 gene expression products. Biochemistry (Moscow), 74, 1239-1252. doi:10.1134/S0006297909110108

[24] Kovaliov, I.E. and Polevaya, O.Yu. (1985) Biochemical grounds for immunity against low-molecular chemical compounds. Nauka Publishers, Moscow.

[25] Kroemer, G., Galluzzi, L., Vandenabeele, P., Abrams, J., Alnemri, E.S., Baehrecke, E.H., Blagosklonny, M.V., El-Deiry, W.S., Golstein, P., Green, D.R., Hengartner, M., Knight, R.A., Kumar, S., Lipton, S.A., Malorni, W., Nunez, G., Peter, M.E., Tschopp, J., Yuan, J., Piacentini, M., Zhivotovsky, B. and Melino, G. (2009) Classification of cell death: Recommendations of the Nomenclature Committee on Cell Death 2009. Cell Death and Differentiation, 16, 3-11. doi:10.1038/cdd.2008.150

[26] Thery, C., Ostrowski, M. and Segura, E. (2009) Membrane vesicles as conveyors of immune responses. Nature Reviews Immunology, 9, 581-593. doi:10.1038/nri2567

[27] Raposo, G., Nijman, H.W., Stoorvogel, W., Liejendekker, R., Harding, C.V., Melief, C.J. and Geuze, H.J. (1996) B lymphocytes secrete antigen-presenting vesicles. The Journal of Experimental Medicine, 183, 1161-1172. doi:10.1084/jem.183.3.1161

[28] Buschow, S.I., van Balkom, B.W., Aalberts, M., Heck, A.J., Wauben, M. and Stoorvogel, W. (2010) MHC class II-associated proteins in B-cell exosomes and potential functional implications for exosome biogenesis. Immunology and Cell Biology, 88, 851-856.

doi:10.1038/icb.2010.64

[29] Backes, C., Ludwig, N., Leidinger, P., Harz, C., Hoffmann, J., Keller, A., Meese, E. and Lenhof, H.P. (2011) Immunogenicity of autoantigens. BMC Genomics, 12, 340. doi:10.1186/1471-2164-12-340

[30] Zaichik, A., Churilov, L.P. and Utekhin, V.J. (2008) Autoimmune regulation of genetically determined cell functions in health and disease. Pathophysiology, 15, 191-207. doi:10.1016/j.pathophys.2008.07.002

[31] Poletaev, A.B., Morozov, S.G., Kljushnik, T.P., Budykina, T.S., Vabishchevich, N.K. and Gnedenko, B.B. (1997) Method for determining neuropsychic diseases development risk degree. RU Patent No. 2147128.

[32] Poletaev, A.B., Abrosimova, A.A., Sokolov, M.A., Gekht, A.B., Alferova, V.V., Gusev, E.I., Nikolaeva, T.Y. and Selmi, C. (2004) Dialectics and implications of natural neurotropic autoantibodies in neurological disease and rehabilitation. Clinical and Developmental Immunology, 11, 151-156. doi:10.1080/10446670410001722221

[33] Quintana, F.J., Getz, G., Hed, G., Domany, E. and Cohen, I.R. (2003) Cluster analysis of human autoantibody reactivities in health and in type 1 diabetes mellitus: A bioinformatic approach to immune complexity. Journal of Autoimmunity, 21, 65-75. doi:10.1016/S0896-8411(03)00064-7

[34] Meroni, P.L., De Angeles, V. and Tedesco, F. (2007) Fu- ture trends. In: Y. Shoenfeld, Gershwin, M. E., Meroni, P.L., Eds., Autoantibodies, Elsevier, Amsterdam, 823-826. doi:10.1016/B978-044452763-9/50105-0

[35] Schmidt, M., Bohm, D., von Torne, C., Steiner, E., Puhl, A., Pilch, H., Lehr, H.A., Hengstler, J.G., Kolbl, H. and Gehrmann, M. (2008) The humoral immune system has a key prognostic impact in node-negative breast cancer. Cancer Research, 68, 5405-5413. doi:10.1158/0008-5472.CAN-07-5206

[36] DiBello, J.R., Kraft, P., McGarvey, S.T., Goldberg, R., Campos, H. and Baylin, A. (2008) Comparison of 3 methods for identifying dietary patterns associated with risk of disease. American Journal of Epidemiology, 168, 1433-1443. doi:10.1093/aje/kwn274

[37] Korkusuz, H., Esters, P., Huebner, F., Bug, R., Ackermann, H. and Vogl, T.J. (2010) Accuracy of cardiovascular magnetic resonance in myocarditis: Comparison of MR and histological findings in an animal model. Journal of Cardiovascular Magnetic Resonance, 12, 49. doi:10.1186/1532-429X-12-49

[38] Pawlak, A., Walczak, E., Gil, R.J., Wagner, T., Rzezak, J. and Seweryniak, P. (2005) Is diagnostic myocardial biopsy useful in the XXI century? Kardiologia Polska, 62, 360-371.

[39] Chow, L.H., Radio, S.J., Sears, T.D. and McManus, B.M. (1989) Insensitivity of right ventricular endomyocardial biopsy in the diagnosis of myocarditis. Journal of the American College of Cardiology, 14, 915-920. doi:10.1016/0735-1097(89)90465-8

[40] Hauck, A.J., Kearney, D.L. and Edwards, W.D. (1989) Evaluation of postmortem endomyocardial biopsy specimens from 38 patients with lymphocytic myocarditis: Implications for role of sampling error. Mayo Clinic Proceedings, 64, 1235-1245.

[41] Brown, C.A. and O'Connell, J.B. (1996) Implications of the Myocarditis Treatment Trial for clinical practice. Current Opinion in Cardiology, 11, 332-336. doi:10.1097/00001573-199605000-00014

[42] Griffin, B.P. and Topol, E.J. (Eds.) (2009) Manual of Cardiovascular Medicine. Lippincott Williams \& Wilkins, Philadelphia.

[43] Friedrich, M.G., Sechtem, U., Schulz-Menger, J., Holmvang, G., Alakija, P., Cooper, L.T., White, J.A., Abdel-Aty, H., Gutberlet, M., Prasad, S., Aletras, A., Laissy, J.P., Paterson, I., Filipchuk, N.G., Kumar, A., Pauschinger, M. and Liu, P. (2009) Cardiovascular magnetic resonance in myocarditis: A JACC White Paper. Journal of the American College of Cardiology, 53, 1475-1487. doi:10.1016/j.jacc.2009.02.007

[44] Maisch, B., Drude, L., Hengstenberg, C., Hufnagel, G., Schonian, U. and Schwab, D. (1992) Cytolytic anticardiac membrane antibodies in the pathogenesis of myopericarditis. Postgraduate Medical Journal, 68, 11-16.

[45] Maisch, B., Deeg, P., Liebau, G. and Kochsiek, K. (1983) Diagnostic relevance of humoral and cytotoxic immune reactions in primary and secondary dilated cardiomyopathy. The American Journal of Cardiology, 52, 10721078. doi:10.1016/0002-9149(83)90535-0

[46] Caforio, A.L., Tona, F., Bottaro, S., Vinci, A., Dequal, G., 
Daliento, L., Thiene, G. and Iliceto, S. (2008) Clinical implications of anti-heart autoantibodies in myocarditis and dilated cardiomyopathy. Autoimmunity, 41, 35-45. doi:10.1080/08916930701619235

[47] Taneja, V., and David, C.S. (2009) Spontaneous autoimmune myocarditis and cardiomyopathy in HLA-DQ8. NODAbo transgenic mice. Journal of Autoimmunity, 33, 260-269. doi:10.1016/j.jaut.2009.09.005

[48] Estrin, M. and Huber, S.A. (1987) Coxsackievirus B3induced myocarditis. Autoimmunity is L3T4+ T helper cell and IL-2 independent in BALB/c mice. American
Journal of Pathology, 127, 335-341.

[49] Fairweather, D. and Cihakova, D. (2009) Alternatively activated macrophages in infection and autoimmunity. Journal of Autoimmunity, 33, 222-230. doi:10.1016/j.jaut.2009.09.012

[50] Wang, J., Okazaki, I.M., Yoshida, T., Chikuma, S., Kato, Y., Nakaki, F., Hiai, H., Honjo, T. and Okazaki, T. (2010) PD-1 deficiency results in the development of fatal myocarditis in MRL mice. International Immunology, 22, 443-452. doi:10.1093/intimm/dxq026 